\title{
TE AO MĀORI IN A "SYMPATHETIC" LEGAL REGIME: THE USE OF MĀORI CONCEPTS IN LEGISLATION
}

\author{
Arnu Turvey*
}

\begin{abstract}
The incorporation of Māori concepts into legislation has been one of several methods the government has employed to acknowledge and promote Māori cultural identity and give practical effect to the Treaty of Waitangi within its legislative frameworks. While legal recognition of Mãori concepts may have appeared as a positive step towards the creation of a mutually beneficial level of bicultural discourse in the government's management frameworks, in practice they have been the source of a new set of challenges. By transplanting Māori concepts directly into legislation, Māori ideas must become operational parts of Western regimes; concepts which are to be recognised and given effect to within the decision-making processes of bodies charged with the administration of particular legislation as well as the courts. Drawing on Commons' observations about the nature of artificial selection - the process by which the meaning of ideas and language is consciously or subconsciously manipulated by the group in power in order to advance its own interests, it becomes evident that, in the context of the common law legal system, Māori concepts have become detached from their original purpose and meaning.
\end{abstract}

\section{INTRODUCTION}

The incorporation of Māori concepts into legislation has been one of several methods the government has employed to acknowledge and promote Māori cultural identity and give practical effect to the Treaty of Waitangi within its legislative frameworks. This process has been part of what Paul McHugh has described as a conscious effort by government and Māori to move from the embattled processes of rights recognition to reconciliation through the development of a "sympathetic legal regime" which "accommodates the cultural disposition" of indigenous groups. ${ }^{1}$

* Submitted as part of the LLM programme at Victoria University of Wellington. I would like to acknowledge the assistance of Māmari Stephens.

1 PG McHugh Aboriginal Societies and the Common Law: A History of Sovereignty, Status and Selfdetermination (Oxford University Press, New York, 2004) 55 [McHugh]. 
While legal recognition of Māori concepts may have appeared as a positive step towards the creation of a mutually beneficial level of bicultural discourse in the government's management frameworks, in practice they have been the source of a new set of challenges. Through the incorporation of traditional Māori concepts into legislation, the legal system has become entangled in a series of highly problematic, post-colonial issues of cultural positioning and representation.

Māori culture is at a crucial stage of development in which important decisions must be made about how its traditional concepts and practices are to take form within a post-colonial world. Both the incorporation of Māori concepts into legislation and the interpretation and implementation of those concepts by the courts and relevant legal authorities have raised questions about the ability of Western institutions to properly consider and apply Māori concepts in a way that will promote rather than subvert Māori culture.

With reference to John R Commons' concept of "artificial selection" this paper highlights the implications of transplanting concepts from one culture directly into the legal system of another, by which they are subjected to processes of selection, translation and interpretation by authorities, and through systems, which are based on a different world view. ${ }^{2}$

Drawing on Commons' observations about the nature of artificial selection, and following a formal exercise which explores the process of legal recognition of the concept of kaitiakitanga, it becomes evident that, in the context of the common law legal system, Māori concepts have become detached from their original purpose and meaning. They have come to serve as text that takes its meaning from the context in which it operates, within the process of two groups of unequal power negotiating their respective positions in a post-colonial, political discourse. In this sense the words themselves have become less part of the Māori world than politicised gestures of cultural recognition.

Māori concepts in legislation represent hard-won victories of claims to cultural recognition. However, on the basis of Commons' observations of sovereign control they may equally represent a further entrenchment of Crown control, one which advances deep into Māori culture. The government's selective recognition and interpretation of Māori concepts as a means of racial reconciliation can be seen in terms of the development of a legal framework which, while sympathetic to Māori, has also served to reinforce its monopolisation of the process of artificial selection. This monopolisation has undermined the authority of Māori over their own culture in decisions about how their own concepts should be applied in contemporary contexts.

All this poses a difficult question for Māori in terms of taking their culture forward; whether the opportunities for legal recognition of important cultural concepts outweighs the risks of subjecting those concepts to Western decision-making processes. Of note here is cultural theorist Stuart Hall's

2 Richard Dawson The Treaty of Waitangi and the Control of Language (Institute of Policy Studies Victoria University of Wellington, Wellington, 2001) 163 [Dawson]. 
description of how the creation of a fictionalised image of a unified cultural group is necessary in order to facilitate that marginalised group's claims to recognition. ${ }^{3}$ Hall adds that, post-recognition, there is a necessary shift in focus for cultural politics. This shift involves the deconstruction of artificially created notions of identity, and the empowerment of the members of the group to define their identity on their own terms. ${ }^{4}$

Hall's discussion (when applied to the New Zealand context - Hall refers to blacks in Britain), points to a further stage in the government-Māori relationship. The further stage is about the politics of representation itself. It necessitates the empowerment of Māori in decision-making processes which determine significant questions about how to define and apply customary concepts.

This paper concludes that, while the current set of institutional arrangements may have been capable of facilitating the recognition of Māori culture in terms of common law reasoning and principles, developing legal frameworks which can allow Māori culture to develop on its own terms present a new, more subtle set of challenges. Such challenges require a more sophisticated set of institutional arrangements. While the exact nature of institutional reform will depend on the circumstances in which it is to operate, as a basic principle, a level of authority for Māori over decisions which affect the development of their culture is required. Rather than limited and politically motivated recognition of a select set of cultural concepts, legal frameworks must be developed which allow Māori to properly consider and provide responses to issues as they arise in accordance with their entire value system.

\section{A "SYMPATHETIC" LEGAL REGIME}

The arguments in this article are set against a backdrop of Treaty jurisprudence and common law rights recognition. While this article is not directly concerned with questions about recognising or denying Māori rights, it is useful to outline the process of rights recognition which led to the legislative inclusion of Māori concepts, as it provides the context and ongoing conceptual framework from which this phenomenon has emerged and continues to operate.

Paul McHugh has outlined a three-stage process of indigenous rights recognition and reconciliation. McHugh describes those stages in terms of a long period of rights denial which was followed, over the last 30 years, by a period of recognition in a judicial climate increasingly sensitive to indigenous common law rights based claims - "the recognition period". 5 The third phase, to which the legislative incorporation of Māori concepts belongs, can be seen as a post-

3 Stuart Hall "New Ethnicities" in David Morley and Kuan-Hsing Chen (eds) Stuart Hall: critical dialogues in cultural studies (Routledge, London and New York, 1996) 441-445 [Hall].

4 Ibid.

5 McHugh, above n 1, 55. 
recognition phase. This period is defined by the challenges posed by downstream questions of how, once recognised, indigenous rights interact with the rights of the wider community. ${ }^{6}$

Generally speaking, New Zealand's recognition period resulted in the re-establishment by the courts and Waitangi Tribunal of the fiduciary rights and obligations of the partnership entered into by Māori and the Crown through the Treaty of Waitangi. ${ }^{7}$ New Zealand's Treaty jurisprudence looked to what it saw as the essential agreement: a willing exchange, for mutual benefit, of the right and duty to make laws for the good of all New Zealanders (Article One - kawanatanga) with the obligation on the Crown to recognise and actively protect the authority of Māori over their lands, resources, and other taonga (Article Two - tino rangatiratanga). ${ }^{8}$

As interpreted by the Waitangi Tribunal and the Court of Appeal, the Treaty principles provide a framework for the recognition and active protection of Māori culture, including its right to develop within an overarching system of Crown sovereignty and the rule of law. ${ }^{9}$ It became apparent, however, that it is beyond the powers of the courts to repair the relationship between the Crown and Māori. ${ }^{10}$ It was up to the Treaty partners themselves to look for ways to address their responsibilities to each other. ${ }^{11}$ The next phase of Crown-Māori relations (McHugh's postrecognition phase) was motivated by the ideal that open dialogue and participatory management would allow New Zealand to move on from the conflict of rights recognition to a more harmonious and productive political setting. ${ }^{12}$

Accommodating the Māori voice in legislation through specific recognition of Māori concepts, as well as Treaty references and the establishment of consultation provisions, became an accepted means through which the government looked to honour the special status of Māori as the Treaty partner. ${ }^{13}$ Throughout the 1990 s and early 2000 s there came a raft of legislation which incorporated

6 Ibid.

7 Ibid.

8 Te Puni Kōkiri He Tirohanga o Kāwa ki te Tiriti o Waitangi: A Guide to the Principles of the Treaty of Waitangi as expressed by the Courts and the Waitangi Tribunal (Te Puni Kōkiri, Wellington, 2001) 49-64 and 77-105. See also Waitangi Tribunal Report on the Muriwhenua Fishing Claim:Wai 22 (Department of Justice, Wellington, 1988) 200 for discussion of the Treaty principles.

9 Waitangi Tribunal Kaituna River Report: Wai 4 (1984) 18 and McHugh, above n 1, 534.

10 In Te Waka Hi Ika O Te Arawa v Treaty of Waitangi Fisheries Commission (HC, Wellington, 3 December 1999) Anderson J held that "... the great issue of Māori fisheries is an inapt dispute for litigation. Its scope in terms of history, culture, economics, politics and policy is so great that the court, however, willing to assist, is an inadequate instrument for the resolution of the difficulties. The courts have tried ... but a broader jurisprudence is required." Sourced from McHugh, above n 1, 522.

11 McHugh, above n 1, 527.

12 Ibid, 521.

13 Ibid, 541. 
requirements to act in accordance with the Treaty principles and in some cases, specific references to Māori cultural concepts. The Resource Management Act 1991, for example, with its references to wāhi tapu, kaitiakitanga and mana whenua, or Te Ture Whenua Māori Act 1993 (which refers to concepts such as whangai and tikanga Māori), and the terms mauri and rahui included in settlement legislation.The term tikanga Māori has also been incorporated into much legislation as a means for recognising (in very general terms) the Māori cultural customs and practices which are relevant in a particular situation. ${ }^{14}$

While these provisions promised legal recognition of Māori views, as McHugh's model of rights recognition demonstrates, the complexities of providing for the cultural values and practices of Māori, when placed side by side with the values and interests of the wider community, has been the basis for much conflict. The incorporation of Māori concepts into legislation and the interpretation of those concepts in decision-making has raised questions about the ability of Western institutions to properly consider and apply Māori concepts in a way that will, as the Treaty requires, actively protect Māori culture and allow it to develop on its own terms within an overarching framework of Crown sovereignty.

\section{PROMOTING IDENTITY: THE POLITICS OF CULTURAL REPRESENTATION}

The incorporation of Māori concepts into legislation arguably goes further than other similarly motivated legal provisions such as requirements to consult. By transplanting Māori concepts directly into legislation, Māori ideas must become operational parts of Western regimes; concepts which are to be recognised and given effect to within the decision-making processes of bodies charged with the administration of particular legislation as well as the courts.

If done properly, this is arguably the furthest the government has gone towards facilitating biculturalism within its legal frameworks. In practice, however, the challenges which arise in the proper implementation of these provisions hit a series of complex, post-colonial issues of representation, restructuring, and repositioning of indigenous cultures within colonially based power structures.

Outside the legal system, an extensive discourse has developed around the subject of representing indigenous or otherwise marginalised cultures within Western cultures, for example the media, museums and art galleries. A major concern lies in the lack of cultural neutrality of Western institutions. There is an inherent problem in that any attempt to represent the image of another culture unavoidably builds on Eurocentric preconceptions and only serves to increase their bearing on other cultures.

14 Tikanga Māori is recognised in s 39 of the Resource Management Act 1991 and defined by s 4 of the Te Ture Whenua Māori Act 1993 as "Māori customary values and practices". 
On this issue, Jamaican-born cultural theorist Stuart Hall has pointed out that recognition of marginalised cultural groups within Western mediums of communication necessarily involves the creation of a fictionalised, unified group in order to facilitate claims to representation (or cultural recognition). ${ }^{15}$ Consequently the values of members of that wider group are seen in simplified and subsequently limiting terms, defined by a constructed image of a homogenous cultural group.

Attempts to value and reinstate the culture of marginalised groups tend to look to preserve and protect traditional characteristics in terms of a perceived authentic state or in terms of Hall's image of a positive, unified group. The construction of the idea of a wider homogeneous group of Māori (as opposed to tribal identity) and the representation of this group through the recognition of specific concepts may be seen as an example of this.

Importantly, Hall observes that, while the development of this simplified, cultural image is a necessary part of the recognition and de-marginalisation of a cultural group, there is a second phase which moves on from claims to representation (or in this instance recognition) to the politics of representation itself. ${ }^{16}$ In Hall's model, which loosely echoes and further illuminates McHugh's third post-recognition phase, a necessary focus on the politics of representation itself occurs. ${ }^{17}$ This involves breaking down the fictionalised, unified group and dispelling limiting definitions of racial identity which define the experiences of the individuals within that group based on the perceptions of what is and is not an authentic aspect of that culture. The objective is for members of the group to freely assert their culture in the forms they choose, according to their varying sets of values and complex, multifaceted identities. This point is picked up again in the section on Western systems as agents of change (Part VII below).

Hall's observations demonstrate what a complicated matter recognising and protecting cultural identity is. On this point he states: ${ }^{18}$

Identity is not as transparent or as unproblematic as we think. Perhaps instead of thinking of identity as an already established fact, which new cultural practices then represent, we should think of identity as a 'production' which is never complete, always in process, and always constituted within, not outside, representation.

Indeed, Māori concepts are evolutionary and dynamic. Any effort to recognise and protect Māori concepts raises questions about the contemporary interpretation and application of traditional views, beliefs and practices. Such questions include: what new forms should traditional practices take? What is a legitimate extension of a customary practice and how should customary principles

15 Hall, above n 3, 441-445.

16 McHugh, above n 1, 55.

17 Hall, above n 3, 441-445.

18 Stuart Hall "Cultural Identity and Diaspora" (1989) 36 Framework 222, 222. 
apply to new situations in which Māori find themselves or wish to proactively pursue? These are extremely difficult issues which are part of any colonised culture's path of post-colonial reconstruction.

Consequently, the question arises: how should Parliament and the legal system go about recognising Māori concepts? Should they be looking to give effect to Māori concepts by reproducing an authentic meaning of a term in a new context? Should the decision-makers, as Hall described, be looking to unearth "that which colonial experience buried and overlaid, bringing to light the hidden continuities it suppressed"? Or should the system enable the "on-going process of the production of identity"? ${ }^{19}$

In line with the third option, the focus of commentators such as Hall has been to open up discussions of identity; to expose bias, assumptions and constricting definitions of culture in order to create an environment in which constructive discourse about the evolution of cultural identity can occur, unhampered by Eurocentric preconceptions of authenticity. Much of the focus of this discourse is aimed at reasserting the position of indigenous groups as one of authority in reclaiming their right to determine the direction of their cultural practices in their own terms and, as Hall observes, to enable the on-going production of identity. Similarly, what is needed in the legal and political frameworks is not merely recognition of aspects of Māori culture within Western frameworks but rather a serious process of questioning and exposing the levels of underlying cultural bias, and of actively empowering Māori in the institutions themselves.

\section{SOVEREIGN CONTROL AND THE PROCESS OF ARTIFICIAL SELECTION}

Protecting and preserving Māori culture is a complicated process. It can have profound effects on the cultural traditions of Māori, potentially debasing important concepts and parts of the culture and isolating them from their wider value and knowledge systems. Consequently, questions need to be asked about the level of cultural bias that exists within the current institutional structures and accordingly their ability to allow for the unhampered production of cultural identity within them.

The concept of artificial selection, as developed by Commons in the early $20^{\text {th }}$ century, offers some useful insights for examining the effects of the incorporation of Māori concepts into legislation. Richard Dawson in his article "Artificial Selection in Colonial New Zealand" applies, to the New Zealand context, Commons' concept of artificial selection to show how words and customs are subject to manipulation by the group that holds sovereign power, and who will inevitably select and interpret them in ways that suit the group's own values and interests. ${ }^{20}$

19 Ibid.

20 Richard Dawson "Artificial Selection in Colonial New Zealand" (1999) 7 Waikato LR 4, 4-7. 
Richard Dawson employs Commons' theory that sovereignty is in fact a struggle for the control over the process of artificial selection and therefore the determination of whose principles, rules and values should prevail. With this, Dawson examines how, during the period from 1830 to 1880 , the British Crown and then the settler government constructed an institutional structure designed to take the sovereign sanction of force from the rangatira and tohunga who had up until then controlled the process of artificial selection in New Zealand. In particular, based on Commons' observations about the function of language as a tool of negotiation, Dawson considers that the British Sovereign's control of the process of drafting and later interpreting the Treaty of Waitangi provides a strong example of artificial selection in action. ${ }^{21}$

Commons, Dawson states, outlined the complex process by which the state is an object of "control and capture in regard to channelling the direction of artificial selection, that is, the determination of whose customs are to count and whose to perish". ${ }^{22}$ Integral to Commons' theory is the notion that customs evolve on the basis of conscious decisions intended to achieve favourable outcomes for the group in control, according to Dawson. All laws, rights and customs are changing practices reinforced by their continued acceptance by a community or an institution. ${ }^{23}$

As Commons has outlined, at the political level the law-maker determines the outcomes of human interactions by recognising values, principles and beliefs as being valid customs or rights. ${ }^{24}$ In this regard, Commons equates legal rights with customs, pointing out that the state, which has sovereign powers, creates rights on the basis of its selection of some human practices over others which it prefers on the basis of the outcome of those practices. ${ }^{25}$ This view rejects the positivist standpoint that rights have an inherent existence that it is the role of the state to detect and protect. When broken down to this level of personal preference the cultural values of the sovereign group become paramount.

Dawson describes Commons' theory of artificial selection in the following way: ${ }^{26}$

The contingent nature of customs often becomes apparent when they come into conflict with other customs following a change in circumstances such as an increase in population. It is at this point of rights integration where deliberate decision-making is required over whose custom will count and whose will not.

21 Ibid, 12

22 Ibid, 5.

23 Ibid, 2.

24 John R Commons The Legal Foundations of Capitalism (The Macmillan Company, New York, 1924) 299.

25 Dawson, above $\mathrm{n} 20,4$

26 Ibid. 
The position of the government in controlling artificial selection equates to a monopolisation of the process of selection and determination of what are deemed to be good customs and the elimination of what are deemed to be bad customs. ${ }^{27}$

Once the government has recognised particular customs or rights, the courts then determine the outcomes of disputes that arise from the application by individuals of these customs to specific sets of circumstances. Both processes bring into play the underlying concepts and values of the decisionmaking bodies. Commons' theory dictates that such decisions will not go against the values of the decision-making power. Even if they appear to be in someone else's interests (as in the case of recognising Māori concepts) they will fundamentally be based on a desire or political motivation of the power-holding group. However sympathetic the dominant group may be, its decisions will be determined by its own underlying principles and cultural values.

Of particular relevance to the incorporation of Māori concepts in legislation is Commons' discussion of the fluid and easily influenced meaning of words. Commons states that "contests to control and use sovereignty for the purposes of channelling artificial selection, ultimately involve attempts to control and manipulate language". ${ }^{28}$ Commons rejects formalist views that words have a clear meaning, noting that they are part of the evolving nature of culture and change according to the context in which they are applied: "Words as cultural artefacts, encapsulate changing interpretations of experiences and values. Changes in the meanings of words are correlated with cultural change". ${ }^{29}$ Commons goes on to state that: ${ }^{30}$

The common law itself is only the decisions of disputes according to the prevailing customs. Between the multitude of competing precedents there is opportunity for judges to select, so that the common law changes and grows by artificial selection looking towards future consequences.

From Commons' observations we can see that the incorporation of cultural concepts into a context in which one side has a monopoly over determining which terms are selected, how they are incorporated, and how they are to relate to other concepts and values will lead to subtle, or not so subtle, manipulations of the meaning of key concepts to suit the interests and underlying ideology of the dominant group. ${ }^{31}$ In other words, it is impossible to be neutral when deciding outcomes between various interest groups, no matter how sympathetic the regime - there will always be some level of subjective evaluation from the dominant group.

\footnotetext{
27 Ibid

28 Commons, above n 24, 9.

29 Ibid, 299

30 Ibid.

31 Ibid.
} 


\section{ARTIFICIAL SELECTION IN POST-COLONIAL NEW ZEALAND}

Dawson uses Commons' concept of artificial selection to examine how the settler government asserted control over the process of artificial selection in the $19^{\text {th }}$ century to advance the interests of colonialism. This period saw tribal Māori lose nearly all influence over the process of artificial selection in New Zealand. In their place came the empowerment of a colonial government which, over the next century, pursued a line of artificial selection so radically based on its own values and ideas that it all but destroyed Māori cultural customs.

In contrast to Dawson's article, this article examines how, within the period of post-colonialism and Māori rights reconciliation over one hundred years on, the government has attempted to recognise the Treaty relationship within the same institutional frameworks that once debased Māori interests, through strategic concessions in the artificial selection process.

Viewed sceptically, the incorporation of Māori concepts into its legislation could be seen as the government accommodating Māori values in its own decision-making process in order to defuse growing challenges to its right to exclusive sovereignty. ${ }^{32}$ The government has not relinquished its position of authority in determining the outcomes of artificial selection but has made concessions to recognise the rights of another group within the process of determining the question: "whose custom will count and whose will not?"33

The next section looks to highlight in closer detail how the government's continued control over the process of artificial selection affects the meaning and function of important parts of Māori culture. It does this by dividing the process of legal incorporation and implementation into points at which the law-maker and later the decision-maker must act or interpret in ways that influence the terms' meaning through their own preference or underlying ideology.

\section{A Selection}

Legal recognition of a term automatically adds new functions to its meaning. Immediately it becomes part of a new body of knowledge, principles and values. The type of legislation and the function the term or the weight it is given within that law serve to determine the concept's new role and significance.

The effect of selecting certain terms over others also has implications for cultural change. Certain terms such as kaitiakitanga and rahui become part of the popular vocabulary of a specialist area of law, potentially eclipsing other relevant terms to which they are traditionally interrelated and limiting their effect in other areas in which they would otherwise equally apply. This selection process involves favouring particular aspects of a culture and carries with it loaded meaning. For

32 Dawson, above n 2, 163.

33 Commons, above n 24, 299-300. 
example, the government is highly unlikely to select concepts that do not correspond with its own political objectives.

Also relevant is the area of law into which concepts have been incorporated, for example whether certain Māori terms have been used more frequently in environmental and family law rather than property, business or criminal law. Based on a brief survey of legislative references to Māori concepts, the vast majority of Māori concepts appears in environmental law as well as the law surrounding local government. Some appear in family law. An example is the reference to whānau in the Children, Young Persons, and their Families Act 1989. Another example, around which a significant amount of case law has demonstrated the tensions of cross-cultural interpretation, is whāngai which is used in Te Ture Whenua Māori Act 1993, section 115. Few Māori concepts are to be found in commercial and criminal law, although the Te Ture Whenua Māori Land Act 1993 has applied Māori concepts to property law.

\section{B Statutory Definition}

In most instances the incorporation of a Māori concept into law has been accompanied by a statutory definition. While used to provide assistance to people interpreting and applying the law, such translations are highly problematic and often create new uncertainties. Using an English translation almost inevitably undermines the value of the term from the very start. The Ministry of Justice report Guardianship, Custody and Access: Māori Perspectives and Experiences (the Justice report) highlights the issues in defining meaning through cross-cultural referencing by quoting Joan Metge: ${ }^{34}$

To come to grips with Māori custom law, it is necessary to recognise that Māori concepts hardly ever correspond exactly with those Western concepts, which they appear, on the surface, to resemble. While there is a degree of overlap, there are usually divergences as well. Even if the denotation - the direct reference - is substantially the same, the connotations are significantly different.

The Justice report goes on to discuss the tendency to define Māori concepts in relation to Pākehā ones. It states that this results in "shallow explanations of Māori concepts that fail to source them in their own unique philosophical underpinnings." 35 It goes on to state that Māori concepts do not exist merely as counterpoints to Western legal concepts. Rather, they are drawn from their own systems of knowledge, based on a different world view. ${ }^{36}$ Emphasising commonalities between Māori views and those of Pākehā may have been used as a means for justifying inclusion of Māori

34 Joan Metge "Commentary on Judge Durie's Custom Law" (unpublished paper for the Law Commission, 1996); cited in Di Pitama, George Ririnui and Ani Mikaere Guardianship, Custody and Access: Māori Perspectives and Experiences (Ministry of Justice, Wellington, 2002) para 7.1.

35 Di Pitama, George Ririnui and Ani Mikaere Guardianship, Custody and Access: Māori Perspectives and Experiences (Ministry of Justice, Wellington, 2002) para 7.1.

36 Ibid. 
interests to the wider public. This, however, involves moderating the more mystical aspects of the Māori world view in favour of the practical and common sense interpretations of Māori views and practices from a Western perspective. ${ }^{37}$

The term "in accordance with tikanga Māori" has been added to the legislative definitions of many Māori terms to address the inadequacy of English definitions of Māori concepts. This contradicts the purpose of providing a definition by creating uncertainty about what tikanga Māori may mean in any particular circumstance. This uncertainty around a reference to the world from which the term is derived may, however, have the positive result of encouraging decision-makers to look to Māori experts for guidance on interpretation, and therefore empower Māori in the process of definition, if not in the decision about how that term should be applied to the facts of the case.

This uncertainty is a major factor in the both the argument for and against the inclusion of Māori terms in legislation. As noted, the uncertainty of meaning can necessitate a Māori interpretation. However, without the decision-making model in place to allow this to occur in a formal and reliable way, the process is open for abuse. There are no externally obvious checks and balances on the process to ensure that any Māori interpretation given is culturally informed and not biased so as to advance the interests of an individual litigant.

\section{Interpretation}

As Commons states, words are not real - "they are signs and symbols". ${ }^{38}$ Changes in the meaning of words correspond with cultural changes. ${ }^{39}$ The meaning of words is determined by their context. In the new context of the common law these words may come to mean very different things from what they did in the conceptual framework from which they came. These concepts have been transplanted from intricate systems of belief and knowledge and into complicated and politically driven negotiations about social relationships.

Once incorporated into law, Māori concepts become words subject to statutory interpretation and defined according to the court's interpretation of what Parliament intended them to mean. According to Commons, objectivity of the courts is a myth designed, along with other liberalist theories about the free market and minimal role of the state in relation to the affairs of the individual, to entrench one social group's advantaged position within the law. ${ }^{40}$ Specifically,

37 An example is the Waitangi Tribunal's statement in the Manukau Report that "the Māori world view emphasises the primacy of nature and the need for man to tread carefully when interfering with natural laws and processes. But the difference is basically one of emphasis." Waitangi Tribunal Manukau Report: Wai 8 (GP Publications, Wellington, 1985) 91.

Commons. above n 24, 9.

39 Ibid.

40 Commons, above n 24, 347. 
Commons states that "definition is also valuation" and that "legal definitions for the most part are generalisations from judicial experience". ${ }^{41}$ When rights of the wider community come up against the collective right of a tangata whenua group, in determining an outcome the court seeks some external rule that does not change with the set of habits and emotions of a particular individual judge: ${ }^{42}$

But try as they may they cannot escape valuing consciously or unconsciously, by logic or habit, the relative importance of the human interests at stake. Every transaction is weighed at every point according to what is deemed to be a public purpose.

In addition, the government's devolution of the administration of its legislative frameworks to more localised agencies, in particular local government, has created a degree of separation between itself and its Treaty partner. Consequently, while the government has at a high level recognised certain aspects of Māori culture, the decisions about how these rights are to apply in practice have been placed in the hands of another set of authorities, who must carry out their own, more limited, process of artificial selection.

\section{Implementation}

Giving effect to Māori concepts in decision-making processes has resulted in the development of new practices or systems such as consultation mechanisms, advisory bodies or the appointment of new governance or decision-making authorities within traditional Māori frameworks. Participation in Western-based forms or practices has become a part of exercising (or at least protecting) Māori cultural concepts. These processes for expressing cultural concepts could be seen as a genuine extension or development of the culture itself. However, this does not hide the fact that Māori have been forced to adopt Western practices in order to protect (or express) their own culture.

\section{KAITIAKITANGA AS A LEGALLY CONSTRUCTED TERM}

To look at how these processes have shaped the contemporary understanding and function of Māori concepts, the next section uses kaitiakitanga as an example of a legislatively recognised concept. Kaitiakitanga is used because of its fundamental importance in the Māori world view and the fact that it has been incorporated into significant legislation such as the Resource Management Act 1991 and the Fisheries Act 1996. The term is considered in three phases: its pre-legislative meaning; its legislative incorporation (which is broken into the steps outlined in the section above); and post-recognition, where the impact of the term's legislative incorporation on its meaning and function within Māori culture is considered.

\footnotetext{
41 Ibid.

42 Ibid, 326.
} 


\section{A Pre-legislative Meaning}

In order to examine how Māori culture and identity have changed as a response to its incorporation into the legal system, it is necessary to provide evidence of how the concept operated within a Māori world view. Margaret Mutu, as cited by Mere Roberts in Kaitiakitanga: Mãori Perspectives on Conservation, has provided the following description of the term kaitiakitanga: ${ }^{43}$

Kaitiaki is a word derived from the verb "tiaki" (to guard; to protect; to keep: to watch for; to wait for) with the prefix "kai" denoting the doer of the action. Hence a kaitiaki can be translated as a guardian, and kaitiakitanga the act of guardianship.

The concept of kaitiakitanga is inextricably linked with the wider Māori belief system which positions all things in a natural order according to their relationship with atua. ${ }^{44}$ As described by Elsdon Best, the position of kaitiaki originated with the atua children of Rangi and Papa - gods who had responsibilities over particular parts of the natural world. It was their responsibility to "watch over and promote the welfare of all things in all places, to prevent troubles of all kind, to allay all evil to preserve peace among all things". ${ }^{45}$

Nganeko Minhinnick, in her paper Establishing Kaitiaki states: ${ }^{46}$

The traditional institution of Kaitiaki does not stand alone ... it is part of a complex social, cultural, economic, and spiritual system that has been established through long tribal associations with land and waters. To know Kaitiaki is to know the Māori world - the tribal structures of iwi, hapu, whanau. It is only from an understanding of tangatawhenua, manawhenua and ahi kaa that we can begin to appreciate the position of kaitiaki.

Minhinnick's quote clearly describes the broad application and central position of the concept of kaitiaki in the Māori world view. It also states that to understand the concept requires a much broader knowledge of the complex systems from which it originates. Minhinnick adds: "The physical kaitiaki system is based on whakapapa (genealogy) lineage, and inherited nurtured responsibility as in father to son, mother to daughter, or by election, instruction and direction of tribal leaders." 47

43 Mere Roberts, Waerete Norman, Nganeko Minhinnick, Del Wihongi and Carmen Kirkwood "Kaitiakitanga: Māori Perspectives on Conservation" (1995) 2 Pacific Conservation Biology 7, 12 [Kaitiakitanga].

44 Elsdon Best Some Aspects of Māori Myth and Religion Dominion Post Monograph No 1 (Government Printer, Wellington, 1978) 11.

45 Ibid.

46 Nganeko Kaihau Minhinnick Establishing Kaitiaki (Minhinnick, Auckland 1989) 1.

47 Ibid, 4. 


\section{B Legislative Incorporation}

\section{Selection of kaitiakitanga}

The term kaitiakitanga is used exclusively in resource management law, which is not consistent with its wider use in the Māori world view. ${ }^{48}$ Kaitiakitanga is used in the Resource Management Act 1991 (RMA) which, pursuant to section 7(a), requires decision makers to "have particular regard" to kaitiakitanga.

Other legislative references include section 40(1) of the Foreshore and Seabed Act 2004, which states that one of the purposes of a foreshore and seabed reserve is to "acknowledge the exercise of kaitiakitanga by the applicant group over the specified area of the public foreshore and seabed." The Fisheries Act 1996 has also incorporated kaitiakitanga. Section 4 defines it as "the exercise of guardianship; and, in relation to any fisheries resources, includes the ethic of stewardship based on the nature of the resources, as exercised by the appropriate tangata whenua in accordance with tikanga Māori."

(a) Kaitiakitanga and the Resource Management Act 1991

Kaitiakitanga was first incorporated into the RMA, along with a number of other community or national values, as necessary components of resource management planning and decision-making. These matters are given varying levels of importance. Kaitiakitanga is not included in the highest level, to which requires decision-makers to recognise and give effect, but as an "other matter" which requires decision makers to "have particular regard" to.

Inherent in the RMA's driving concept of sustainable management is an increased level of devolution and participatory management which recognises that decisions about communities are often best made within the local context. The rise of participatory management as an inherent component of sustainable management is linked to wider developments in environmental management at a national/community level as well as internationally that arise from political claims to the right to share resource management power and responsibility with the state. ${ }^{49}$ The inclusion of the Treaty principle reference in section 8, along with the Māori specific provisions in section 6(e) (the relationship of Māori and their culture and traditions with their ancestral lands, water, sites, waahi tapu, and other taonga) and section 7(a), kaitiakitanga was the government's way of recognising the Treaty relationship within its devolved management system and allowing Māori to have a say in environmental matters.

48 Although the Waka Umanga Bill 2007 preamble refers to kaitiaki as a defining feature of Māori groups.

49 Castro Alfonso and Erik Nielsen "Indigenous people and co-management: implications for conflict management" (2001) 4 Environmental Science and Policy 229, 232. 
The RMA effectively shifted the burden of consultation from the government to local government who, in turn, has, where deemed appropriate, shifted the burden onto individual resource consent applicants. Tangata whenua groups have been expected to participate in highly complicated, time-consuming and expensive processes. While central government had passed its legislation on the grounds that it would ensure Māori concepts and a Māori voice were part of the new regime, in practice there was little provision for the complicated and resource-intensive processes that would be required to put this framework into place. The protection of Māori concepts has often been compromised as a result. ${ }^{50}$

\section{Translation of kaitiakitanga}

Section 2 of the RMA defines kaitiakitanga as "the exercise of guardianship by the tangata whenua of an area in accordance with tikanga Māori in relation to natural and physical resources; and includes the ethic of stewardship". The use of the terms "guardianship" and "the ethic of stewardship" in relation to tikanga Māori provides an example of Wright's observation that statutory definitions indicate what kind of thing the concept is, but do not "specify all the values or practices that it can encompass." 51

\section{Interpretation of kaitiakitanga}

The legal conflict that has surrounded the implementation of the RMA's Māori provisions demonstrates the "rampant legalism" which, as McHugh points out, resulted from issues of rights integration in the post-recognition period. This said, case law only represents the rare occasion where a Māori group has had the necessary resources to take a decision to court. Case law does not account for the majority of instances where either Māori have not been involved in important decision-making processes or their concerns have been considered but not given effect to. The tendency to give more weight to the economic interests of resource consent applicants over the less tangible and not well-understood cultural interests of Māori is something which has occurred at both the local government level and in the courts. It is also not unique to Māori interests; other cultural or environmental values have often been outweighed by economic interests under the Act. ${ }^{52}$

The significance of the incorporation of Māori concepts into the RMA is demonstrated by the pre-RMA decision Minhinnick $v$ Waikato Valley Authority A66/84, 1984, in which the Planning Tribunal held that under the Water and Soil Conservation Act 1967 "there is nothing in the Act which allows us to take those purely metaphysical concerns [of Māori] into account." Contrast this

50 Te Puni Kōkiri Te Kotahitanga o te Whakahaere Rawa: Māori and Council Engagement Under the Resource Management Act 1991 (Te Puni Kōkiri, Wellington, 2006) 13 [Te Puni Kōkiri].

51 Fiona Wright "Law, Religion and Tikanga Maori" (2007) NZJPIL 261.

52 David Young Values as Law: The History and Efficacy of the Resource Management Act (Institute of Policy Studies Victoria University of Wellington, Wellington, 2001) 32. 
with the interpretation of kaitiakitanga in the RMA by Chambers $\mathrm{J}$ in Auckland Regional Council v Arrigato Investments Ltd: McDonald v Arrigato Investments Ltd, ${ }^{53}$ who held that, since Parliament had chosen to express section 7(a) of the RMA with a Māori term, the Māori understanding of that term must be paramount. However, it was also considered important that non-Māori speakers be able to understand the concept by the use of appropriate English terminology.

The incorporation of the concept of kaitiakitanga as well as the matters in section 6(e) in the RMA has now made it clear that the courts may consider the spiritual or metaphysical aspects of Māori culture. As the following decisions demonstrate, the courts, under the RMA, have accordingly been willing to consider Māori spiritual and cultural values along with those of the wider community and, at times, have made significant decisions in favour of their protection. But the decisions have demonstrated a tendency of the courts to avoid directly considering the concepts' specific meanings, instead applying them in general terms. For example, there seems to be little distinction in judicial decisions between the application of the concept of kaitiakitanga to the more specific provisions in section 6(e).

The judges in decisions such as those of the Court of Appeal in Watercare Services Ltd $v$ Minhinnick ${ }^{54}$ and the High Court in Ngāti Maru $v$ Kruithof and Thames Coromandel District Council $^{55}$ have looked to develop reasoning and tests for considering Māori culturally-based objections by applying common law concepts such as proportionality and objectivity as standard tests. Decisions on the Māori provisions tend to be based on matters of process (for example whether sufficient consultation has occurred) and reliability of evidence rather than on considerations of the meaning of the Māori concepts themselves.

In Watercare Services v Minhinnick the Court of Appeal approved of the Environment Court's use of a "reasonable Māori person representative of the community at large" test to determine whether Minhinnick's objection to the construction of a sewerage pipeline which travelled over wahi tapu was offensive to such an extent that it would have an adverse effect sufficient to outweigh the values of the community as a whole: ${ }^{56}$

The court must weigh all the relevant competing considerations and ultimately make a value judgment on behalf of the community as a whole. ... the court, as the representative of New Zealand society as a whole, decides whether the subject matter is offensive or objectionable under s314. In the end a balanced judgment has to be made.

53 Auckland Regional Council v Arrigato Investments Ltd: McDonald v Arrigato Investments Ltd (14 September 2000) HC Auckland AP138/99 \& M126-SW00.

54 Watercare Services Ltd v Minhinnick [1998] 1 NZLR 294 (CA).

55 Ngāti Maru v Kruithof and Thames Coromandel District Council (30 July 2004) HC, Hamilton, CIV $2004-$ 485-330.

56 Watercare Services Ltd v Minhinnick [1998] 1 NZLR 294 (CA) 305. 
In light of Commons' commentary on the judiciary's claim to objectivity, this ruling provides an example of a Western body legitimising its own value system as the test for interpreting a Māori concept. Accordingly, Māori concerns are to be considered within a sympathetic regime, but it is the role of an authority with little understanding of a Māori perspective to rule on whether or not the proposed activity is sufficiently objectionable to what it interprets to be a reasonable representative of the Māori community. The court is free to consider Māori interests along with any number of other interests and rule according to its own assessment of the values at stake.

In the examples given, the courts have shown a reluctance to provide definitive interpretations of Māori concepts, relying more on questions of process and tests of reasonableness. While legal recognition has allowed the court to consider the spiritual and intangible cultural effects of a proposed activity, in making this consideration the courts have often applied the concept of kaitiakitanga along with the other Māori concepts in the RMA in a vague, generalised manner. This indicates that the significance of these concepts within the RMA regime has become less in the terms of their original meaning than as symbols of, and tools for, a broader reconciliatory dialogue.

\section{Implementation of kaitiakitanga}

There are examples of the RMA's Māori-specific provisions working well in terms of established relationships between local government and groups. ${ }^{57}$ However, by and large the requirements of participation in planning or resource consent decision-making have presented considerable problems for tangata whenua groups and the agencies they were to engage with. As McHugh states, "the RMA created a consultation regime into which Māori were drawn, like it or not". 58

Protection of cultural values including kaitiakitanga requires a new level of expertise from both Māori and local government. Issues of governance, representation, capacity, and capability have frequently undermined Māori participation in processes that have direct effects on their values. Local governments that have taken their legislative responsibilities to Māori seriously have also struggled with the task of consulting with Māori. The consequence is that advocacy for kaitiakitanga is not as strong many other non-Māori interests. ${ }^{59}$

\section{B Post Recognition Meaning: The Effect on Mäori Culture}

As Cate Poynton states "language constitutes context as well as simultaneously being constituted by it". ${ }^{60}$ In the context of the legal frameworks into which these concepts have been

57 Te Puni Kōkiri, above n 50

58 McHugh, above n 1, 511.

59 Te Puni Kōkiri, above n 50, 8-9.

60 Alison Lee and Cate Poynton (eds) Linguistic and Discourse Analysis: Culture and Text - discourse and methodology in social research and cultural studies (Allen \& Unwin St Leonards, NSW, 2000) 31. 
transplanted, these words have come to take on meanings of their own. Whether these new meanings and functions have replaced the pre-legislative meanings, whether the traditional meanings still operate alongside these new forms, or whether these concepts have been fundamentally altered as part of a wider post-colonial process in the restructuring of Māori cultural identity through adaptation to new contexts are open-ended and culture-defining questions for Māori. On this point, however, Minhinnick states that these terms should be flexible and that it is the underlying intentions which determine whether an act or process is a valid form of kaitiakitanga: ${ }^{61}$

Concepts should be flexible, they are essentially about exercising mana, which has been bestowed upon the kaitiaki (as opposed to self proclaimed) to act as a guardian of something which will ensure its health and the appropriate balance of a natural harmony and hierarchy. So whether it be through litigating in the Environment Court or through more traditional means if a person who has the mandate to act is acting with the same set of intentions about ensuring the health and balance of a system it is a genuine expression of kaitiakitanga.

While it is difficult to determine the precise effects of the inclusion of Māori concepts in legislation on the original concept, it is possible to observe that concepts such as kaitaikitanga have undergone significant transformations in the face of legal recognition. As discussed, the concepts have acquired new meaning less in terms of their traditional cultural values than as mechanisms for facilitating the recognition of Māori interests more broadly. The terms have picked up new means of expression and have become loaded with the baggage of their particular legal framework. Furthermore, in interpretation the concepts have been subject to the courts' creation of a "reasonable Māori person".

\section{WESTERN SYSTEMS AS AGENTS FOR CHANGE}

Māori must decide whether the inclusion of their culture into legal systems which subjects it to non-Māori decision-making authorities is a positive move. This is not a new question for Māori. In the face of colonisation, but even more so now in post-colonialism, Māori have been forced to make important decisions about how to promote their culture and identity and whether to use the same institutions that once so effectively undermined those cultural traditions. Paul McHugh describes the significance of these decisions: ${ }^{62}$

The enduring paradox that aboriginal people faced as they confronted the constitutional system of the settler-state after the war: the more they rejected the outcome of colonialism (its victim hood especially), the more they co-opted (and adapted) key elements of it, such as (most notably) its legalism. For some this was not necessarily a negative as an energizing series of choices in keeping with their history of

61 Kaitiakitanga, above n 43, 12.

62 McHugh, above n 1, 56. 
adaptation and innovation. For others even to talk the language of rights was the antithesis of their aboriginal identity. Part of their own mental colonisation.

Some commentators have criticised moves by government to incorporate the Treaty principles into its frameworks as merely consolidations of current institutional power. Dawson quotes Jane Kelsey as describing the victories of the recognition period as containing the "seeds of long term defeat" 63 in that, by accepting the Crown's watered-down interpretation of the Treaty, the Crown has been allowed to subdue the growing revolt against its complete control of sovereignty. ${ }^{64}$ The inclusion of Māori concepts in legislation, like the Treaty principles, would likely be seen by Kelsey as part of the government's evasion of the conflict between kawanatanga and tino rangatiratanga and the "subordination of Mana Māori to absolute Crown authority". ${ }^{65}$

But for many Māori, the development of a "sympathetic" legal regime has been the result of hard-won battles, be it as they may, fought within the institutions and rules of the English common law. The legalism that characterised the period of rights recognition, while motivated by the feelings of loss, resentment and anger towards the authorities that had denied their status and the Treaty, demonstrated an ongoing willingness from Māori to utilise the opportunities offered by the same system that had taken them away.

There is a strong history of cooperation for mutual advantage in the Māori-government relationship. The incorporation of Māori concepts into the law can be seen as a continuation of a number of strategic initiatives on the part of Māori to appropriate Western systems to advance their own cultural values - the Kingitanga, the Māori Parliament and even the Treaty itself have demonstrated this.

Equally, it is important to note that Māori, some of whom are closely integrated within the government's legal and political institutions, have not been silent voices in these decision-making processes. The incorporation of Māori concepts into legislation is a strong example of a conscious decision by Māori and the government to work towards the recognition and promotion of Māori culture for mutual benefit. From this perspective, working within Western frameworks to advance Māori culture can be seen as a rational response to the realities of cohabitation and even a valid extension of cultural identity. Richard Boast quotes Richard White as stating that, "contact was not a battle of primal forces in which only one could survive. Something new could appear". ${ }^{66}$

"The Treaty of Waitangi and the Control of Language", above n 2, 165.

64 Ibid.

66 Richard Boast "Recognising Multitextualism: Rethinking New Zealand's Legal History" (2006) 37 VUWLR 547, 27. 
The question we come back to then is whether the systems and frameworks into which Māori concepts have been incorporated are capable of allowing, in Hall's words, for the "on-going production" 67 of cultural identity in terms of the Treaty guarantee of tino rangatiratanga. Or is the use of legal systems, no matter how sympathetic, doomed to only reinforce non-Māori authority over the process of artificial selection?

\section{INSTITUTIONAL REFORM}

Dawson says that Brookfield has argued that the current institutional framework is capable of giving effect to the Treaty and bicultural values, if those values were to be properly entrenched: 68

Let the Constitution make clear, through the entrenchment of the Treaty, the bicultural values that are to be protected, and the lawyers will serve those values well, as indeed they already do, Māori and Pākehā judges and lawyers alike on the Waitangi Tribunal.

But Dawson also says that Commons theories highlight that, even if the Treaty was entrenched, there is an inevitable subjectivity in determining how it would be applied. The issue of control of sovereignty cannot be that easily overlooked: "The state is a human artefact - something which individuals and groups endeavour to control to ensure, among other things, the survival of what they deem to be good customs". ${ }^{69}$

Placing Western-based decision-making bodies in positions of control over the process of artificial selection in which they determine culturally significant questions without a complete understanding of the significance of what they are deciding means attempts to define Māori concepts in practical terms so as to give effect to them in decision-making processes can dilute, distort and debase them.

As discussed earlier in this article, Stuart Hall has observed that the development of a simplified, cultural image is a necessary part of the recognition and de-marginalisation of a cultural group. Hall has, however, also pointed to a second phase which moves on from the process of recognition to the politics of representation and the deconstruction of limiting definitions of racial identity. ${ }^{70}$ The objective is for members of the group to freely assert their culture in the forms they choose (to enable a production of identity), according to their varying sets of values and complex, multifaceted identities. In order for this to happen, Māori need to be in a position of power in determining how their culture is recognised and interpreted. Moreover, there need to be effective institutional frameworks which allow Māori to exercise that power.

67 Hall, above n 18, 222.

69 Ibid, 31

70 Hall, above n 3, 441-445. 
Hekia Parata has commented that Māori sovereignty as guaranteed by Article Two of the Treaty is about restoring iwi decision-making. ${ }^{71}$ This does not preclude individual Māori from making personal decisions, nor does it preclude the government from making laws as the overall national framework. It is about the constitutional rights and status of tribes within New Zealand society which in part comprises "the right to control things of importance to them". ${ }^{72}$ Parata goes on to state sovereignty can be expressed in different ways based on the context: ${ }^{73}$

Cultural sovereignty is ownership and control of those characteristics which reflect your culture and

keep it alive - like language, value systems and institutions such as the marae and the whanau.

Māori have indicated a willingness to be part of an inclusive system which, while governed by a majority of non-Māori, respects and will endeavour to protect and promote their culture in accordance with the Treaty of Waitangi. However, without the type of change based on the recognition of cultural sovereignty, as discussed by Parata, which gives Māori a greater level of ownership and control of the process of artificial selection, legislative recognition of Māori concepts will inevitably result in falsely constructed representations of Māori culture.

While this article has not delved into the options for institutional change (and in any case new institutional arrangements will depend on the context it is to operate within) as a basic principle for any institutional reform, it is evident that an institutional structure is needed which allows Māori to respond to issues as they arise on their own terms. In its report Delivering Justice for All the Law Commission recommends that "Pākehā law needs to recognise the autonomy of Māori customs and establish an iwi led decision making process to operate within its legislative frameworks". ${ }^{74}$

The level of autonomy suggested in the Law Commission's recommended model would help address the key issues of influence from government within the process of artificial selection. The question of how Māori interests interact with those of the wider community would, however, still be left open to some extent. This may be an inevitable reality - it is inevitable that some compromises to Māori interests are necessary, as is the case with any societal group. What is important is that Māori have a level of authority in determining what those compromises are. If that is done, then the law is successfully enabling the production of identity, as opposed to undermining the process of cultural evolution by reinforcing non-Māori ideas about what Māori culture should look like.

71 Hineani Melbourne Māori Sovereignty: The Māori Perspective (Hodder Moa Beckett Publishers Limited, Auckland, 1995) 39.

72 Ibid.

73 Ibid.

74 New Zealand Law Commission Delivering Justice for All: A Vision for New Zealand Courts and Tribunals Report 85 (Law Commission, Wellington, 2004) 7. 


\section{CONCLUSION}

There are important processes of cultural restructuring for Māori in post-colonial New Zealand that require decision-making about which customs continue and what form they take. The incorporation of Māori concepts into legislation, while appearing to capture and promote traditional concepts central to Māori identity, has in fact exposed these concepts to processes of selection, interpretation and implementation by Western authorities with little understanding of the systems from which the terms originate.

The continued monopoly of the government and its agencies over the process of what Commons has described as artificial selection means that these concepts in the context of the common law, rather than promoting Māori culture, are being interpreted in accordance with the underlying values and interests of the dominant group. The meaning of the terms themselves becomes subservient to the political objectives of a government which, while sympathetic to Māori interests, is determined to steer away from the underlying questions of tino rangatiratanga.

Stuart Hall has observed that the construction of a fictional image of a unified cultural group which is defined in terms of cross-cultural references to the dominant culture is a necessary part of the recognition or recentralisation of marginalised groups. ${ }^{75}$ Recognition of Māori concepts which build on a conception of Māori culture as a homogenous group with a set of standard, definable values or concepts is an example of this necessary but flawed process. Hall has observed that the next step in the process of genuine recognition of marginalised culture is the politics of representation itself. This involves breaking down preconceived and limiting representations of identity, and provides a useful indication of where the focus of Māori - government relations in McHugh's post recognition phase needs to head.

Rather than aiming to protect artificially selected concepts of Māori culture, there is a need to establish a framework which allows for Māori culture to be expressed and to develop in a way that recognises the complex nature of Māori identity. It must give Māori the power to determine how to respond to various issues and circumstances within new contexts.

75 Hall, above n 3, 441-445. 